\title{
Obesity Acceptance: Recipe For A Pandemic
}

James L. DeBoy, Lincoln University of Pennsylvania, USA

Sally B. Monsilovich, Lincoln University of Pennsylvania, USA

\begin{abstract}
Despite the well-publicized media coverage of the escalating rates of obesity and its comorbidities, the American public seems largely unconcerned. While the reasons for societal inaction to this health dilemma are complex and interdependent, one factor seems particularly salient: obesity acceptance. This article will examine how and why this notion has devolved from acceptance of the person with obesity to acceptance (and in some cases outright celebration) of the condition obesity. Until such melding is separated, real progress in advancing public health in this arena will continue to founder.
\end{abstract}

Keywords: Obesity; BMI; Hypokinetic Disease

\section{INTRODUCTION}

n December 2009, the Lincoln University (PA) faculty rescinded a three year old curricular policy that required students with Body Mass Indices (BMI) greater than 30 (the federal criterion for obesity) to enroll in a "Fitness for Life" class (DeBoy \& Monsilovich, 2011). By virtually all measures, the class was a success as attested by: (a) no student gained weight in the semester-long (15 weeks) duration; (b) all students gained in muscular strength and cardiovascular endurance; and (c) students rated value of course significantly higher than university mean. Yet, despite these positive outcomes, the faculty dropped the placement policy that required the course for students at-risk for hypokinetic disease. Why the sudden change-of-heart? A veritable firestorm of criticism ensued when word of Lincoln's placement policy, i.e., sorting out students with obesity and requiring them to pass the activity-based class, reached beyond the campus community. The allegations of wrong-doing were vociferous, acerbic, and unrelenting. Perhaps, the most damaging assault leveled against the institution was the discrimination assertion - directed against the oldest historically Black college (HBCU) in the nation. After weathering the barrage of reproofs, rebukes, and censures for two weeks, the faculty adopted a placement policy that would simply recommend the much-beleaguered course for students with BMIs greater than 30 in order to end the savage attacks upon the university's commitment to justice, equality, and human dignity. The driving force that hastened the dismantling of a university's well-meaning effort to address this health-related issue can be attributed to a wide-spread public mindset of obesity acceptance.

Sometime over the past 20 years there has been a paradigm shift regarding obesity acceptance. There was a time when obesity was deemed unequivocally unacceptable by wider society. Yesterday's rejection of obesity apparently has been replaced by tolerance, and in some quarters, open embracing today. To be clear, obesity as a condition is the topic under discussion, the person with obesity is not. Some might argue that rejection of one is tantamount to rejection of the other. However, we must disagree with such a conclusion. Do we not abhor cancer and love persons with cancer? Are we not admonished to love the person and fight the disease of alcoholism? Without question we must remain ever vigilant to guard against the person and adverse condition from morphing into one entity... yet such a phenomenon seems to have occurred with obesity in recent years. Attacks on obesity have been equated as attacks on individuals who are obese. This paper will address how and why obesity the condition has made significant gains in tolerance, if not outright promotion. 


\section{OPPONENTS OF OBESITY}

Clearly there are institutions and disciplines that have been (and currently are) adamant in their fight against obesity. Health care providers (medical fields, fitness advocacy groups) quickly come to mind. Obesity is targeted as a threat because of the company that it keeps: hypertension, heart disease, diabetes 2 , and selected cancers, to name but a few of its co-morbidities (Thorpe, Florence, Howard \& Joski, 2004). The fashion industry and the visual media continue to set their standards at the "healthy weight" level for folks in these fields (although the former group has historically erred in its flagrant promotion of the unhealthy under-weight messages). Athletics, both amateur and professional, have sent mixed messages regarding the obesity issue. Most assuredly, the healthyweight athlete is more often the case than not. Exceptions, however, do exist in the world of sports: offensive and defensive football linemen will often exceed 300 pounds with waist circumferences above the 40 inch limit. Not surprisingly, professional football linemen experience a lifespan 17 fewer years than their skilled position counterparts (receivers and defensive backs). Noel et al. (2003) reported that these linemen experienced a greater likelihood of heart disease and stroke when their abdominal fat deposits rise to higher levels. The military/law enforcement fields continue to set maximum standards of weight for recruits as well as minimum scores on selected fitness assessment measures. Dismissal of active members of the armed forces on the basis of exceeding mandated weight does occur. Some 24 thousand Army personnel were discharged between 1992 and 2007 for failure to meet weight/body fat percentage limits (Williamson, Bathalon, Sigrist, Allen, Friedl, Young, et al., 2009). Organized religions, historically, have reprimanded followers for "abusing the temple of the Holy Spirit". However, in recent years (decades?) pastoral sermons that castigate members for gluttony or sloth (inactive lifestyle) seem the exception. When the clergy's girth and weight approach the obese level (like the majority of the congregation), it seems reasonable to overlook a normative, albeit scripturally-prohibited, phenomenon.

\section{WHY OBESITY ACCEPTANCE?}

Obesity is approaching norm status. Perhaps, the most obvious answer can be found in sheer numbers. A critical mass of the U.S. adult population (27\%) is obese (Body mass Index >30) with another $30 \%$ overweight (and particularly close to joining that obesity cohort). Thus, today's norm is overweight/obese (Keller \& Lemberg, 2003).

Obesity is a right. Another critical variable in the obesity acceptance trend is the cherished American ideal of "right to choose". It has been stridently argued from both sides of the political aisle that we have the right to eat ourselves to the grave if that is our decision. Big government, authoritarian neer-do-wells, nor in loco parentis advocates should not trample individual rights. However, the question that must be answered is when, exactly, does the individual's right to choose (poorly) detrimentally affect the welfare of society to the extent that society (as a whole) cannot sustain itself? Is a $27 \%$ obesity rate for adults with a concurrent price tag for medical costs at 125 billion dollars the breaking point? Or do we wait for another 10 years when the cost of obesity co-morbidities reaches 340 billion dollars? Or is the 860-956 billion dollar price tag in the year 2030 the appropriate time to circumvent individual rights? Should we choose to maintain the status quo, whereby individual rights supersede societal need, the economic system enters bankruptcy (Wang, Beydoun, Liang, Caballero, \& Kumanyika, 2008).

There seems to be far more tolerance for self-imposed health concerns (alcoholism, diabetes 2, obesity) than for health concerns that can be attributed to forces external to the individual, e.g., government or corporations. When individuals choose poorly, the consequences appear to be more readily accepted. It is as if the process of choosing mollifies the end product even when the outcome is detrimental. However, when the individual is victim (resultant effect of others' agency), then indignant righteousness manifests itself (clearly, it should). Again, the focal point in both cases is choice -- autonomy is preferred to usurpation...yet the same end-result will be differentially perceived, interpreted, and evaluated.

Eating disorders (anorexia and bulimia) are unhealthy. Could the well-documented negative focus upon hypo-eating disorders (anorexia and bulimia) have played a part in the (reverse) acceptance of obesity? If not-eating and/or purging of ingested foods is bad (which it is), then (over)eating and/or retention of foods is good? 
Obesity reflects food industry success. Indicting corporate America as a leading proponent of our nation's escalating obesity rates seems valid when one compares the serving portions of today to those of 20 years ago. Restaurants and food vendors have super-sized portions dramatically in recent decades. Compounding quantity with substantial increases in fat, sugar and salt to those "man-sized" servings only adds to the contention that the food industry is a player in this obesity epidemic. Whatever the market will bear has justified the preponderance of unhealthy food choices. The public's appetite and consumption of those unhealthy foods drive the market. If you sell it (fat/sugar/salt in jumbo portions), people apparently buy/eat it.

Obesity reflects food marketing success. Packaging sells. Food marketers learned decades earlier that prospective buyers are influenced by food item aesthetics. Color, shape, size, contrasts, pictures, wording, and heft are designed to attract potential buyers' attention. The snack food industry has enjoyed colossal success in this aspect of the marketing campaign. Adding toys, games and other marketing incentives to the food item has been a particularly successful ploy for the fast food industry, e.g., McDonald's Happy Meals.

Denial eliminates anxiety. Mistrust of research findings and government data that document obesity comorbidities could also play a role in obesity acceptance. When individuals with obesity acknowledge the health risks associated with obesity and decide to intentionally ignore those warnings, then cognitive dissonance results. Such dissonance adds to anxiety; the "informed" unhealthy person who decides to "do nothing" creates additional stress. In effect, s/he knows what to do and why to do it but opts out. Such inaction can lead to heightened feelings of guilt, learned helplessness, and depression. In an effort to bypass the cognitive dissonance effect, persons with obesity can search (and find) data and support groups that counter the mainstream findings of obesity-health risks, continue their present lifestyle, and avert intellectual discord. Denial can create a safe haven... in the short term.

\section{FAT ACCEPTANCE MOVEMENT}

The fat acceptance movement has extrapolated its original, noble goal of decreasing discrimination against people who are overweight/obese. Today, however, the National Association to Advance Fat Acceptance (NAAFA) advocates also for the condition obesity. This melding of person with obesity and the condition itself exacerbates the obesity problem.

Most assuredly, we can (and must) love the person but we need not accept nor celebrate the condition. However, the more egregious error of NAAFA and other like-minded organizations (e.g., Health at Any Size) is misleading the public by professing that obesity is not proven to be unhealthy (despite overwhelming information to the contrary). Of course, one can locate studies that cite no relationship between "overweight and longevity" - there are also studies that find no relationship between "cigarette smoking and lung cancer". Journal articles, books, and blogs provide sources of (mis)information even for holocaust deniers. Are there occasions whereby persons with obesity live a long and healthy life? Yes, but those occurrences are the aberrations (statisticians refer to these cases as probable outliers). Citing these renegade studies provides people with obesity a false hope - and provides yet more resistance for changing one's lifestyle. When obesity acceptance proponents raise distracting issues (e.g., eating disorders, alcohol and other drug abusers) rather than directly and honestly deal with the obesity-related comorbidities, then society is harmed. As stated earlier, denial is a coping device designed to protect self-esteem. However, rejection of the intolerable reality comes at a cost - quality and quantity of human life are compromised.

\section{WHEN HELPING IS HURTING}

By all means, we should make the world safer for a heavier population. However, when we do accommodate the larger individual, we are simultaneously decreasing the likelihood that the obese individual will adopt the healthier lifestyle and lose weight. In effect, societal accommodation in the guise of obesity acceptance makes it easier to live the big life thereby perpetuating the health concern. Resolving this dilemma will require formidable measures undertaken at the individual, corporate, and policy-making levels. 


\section{CONCLUSION: STAY THE COURSE}

As suggested earlier, the apparent factors associated with acceptance of obesity are numerous, complex, and deeply embedded in our culture. Not surprisingly, there is no one approach to redress passive or active acceptance of obesity. It is our assumption that human behavior is amenable to change but change often is associated with discomfort -- and with discomfort comes resistance. Opponents of obesity acceptance must be inured against the inevitable fusillade of attacks from those accepting of obesity. As we witnessed in the Lincoln University case, these assaults will be blatant, harsh, passionate, and sometimes ad hominem. Healthcare providers/educators must remain resolute in countering the obesity acceptance trend. Safeguarding the well-being of society requires a commitment that is unwavering, yet sensitive, and capable of responding cogently to all questions, suppositions, and critiques. In short, acquiescing to obesity acceptance is anathema to any helping profession.

\section{AUTHOR INFORMATION}

James L. DeBoy earned a PhD in Human Development (with minor concentrations in Special Education and History of Education) at the University of Delaware. He was appointed to the Lincoln University faculty in 1975 and achieved academic rank of Professor in 2000. As Chair of the HPER Department since 1989, he has served on virtually all major academic committees, assumed the lead role in assessment of student learning outcomes for 20 years, served key roles in the university's re-accreditation process for three decades, and successfully taught more than 10 different health-focused courses over a 35 year career in higher education. Formally educated in the disciplines of Psychology, Special Education, and Physical Education/Adapted Physical Education, Dr. DeBoy embraces the methodological contributions of each particular field to the realization of a "healthier people". He has presented papers at regional, national, and international conferences on such diverse topics as motor development, alcohol abuse prevention, student learner outcomes in health sciences, human cognition/metacognition, and obesity testing across the curriculum. E-mail: Luhper1111@aol.com. Corresponding author.

Sally Wagner-Monsilovich earned an Ed.D in Health Education at Temple University, Pennsylvania. She was appointed to the Lincoln University faculty in 1990 and currently holds the Associate Professor rank. She has served on many major academic committees, successfully taught many courses in the Health Science Department over the last 20 years, and has taught/led myriad health fitness programs in the community. Her areas of specialty include: nutrition, fitness and body image in relation to obesity.

\section{REFERENCES}

1. DeBoy, J. L., \& Monsilovich, S. B. (2011). Mandating obesity testing across the curriculum: Lessons learned. American Journal of Health Sciences, 2(1), 29-33.

2. Keller, K. B., \& Lemberg, L. (2003). Obesity and the metabolic syndrome. American Journal of Critical Care, 12, 167-170.

3. Noel, M. B., VanHeest, J. L., Zaneteas, P., \& Rodgers, C. D. (2003). Body composition in division I football players. Journal of Strength and Conditioning, 17(2), 228-237.

4. Thorpe, K. E., Florence, C. S., Howard, D. H., \& Joski, P. (2004). The impact of obesity on rising medical spending. Health Affairs, w4, 480-486.

5. Wang, U., Baydoun, M., Liang, L., Caballero, B., \& Kumanyika, S. (2008). Will all Americans become overweight or obese? Estimating the progression and cost of the US obesity epidemic. Obesity, 16(10), 2323-2330.

6. Williamson, D. A., Bathalon, G. P., Sigrist, L. D., Allen, H. R., Friedl, K. E., Young, A. J., et al. (2009). Military services fitnessdatabase: Development of a computerized physical fitness and weight management database for the U.S. army. Military Medicine, 174(1), 1-8. 